\title{
Environmental impact of potato cultivation on plantations covering areas of various sizes
}

\author{
Zbigniew Kowalczyk ${ }^{1, *}$ \\ ${ }^{1}$ Department of Production Engineering, Logistics and Applied Computer Science, Faculty of \\ Production and Power Engineering, University of Agriculture in Cracow, Poland
}

\begin{abstract}
The paper contains a comparative analysis of technologies used for potato production on plantations covering areas of various sizes in the context of their impact on the natural environment. The research was conducted for potato plantations in the south of Poland. For its purposes, the "cradle-to-gate" approach was adopted. The type of technological practices applied were taken into account, as well as machines used, duration of their operation, number of seed potatoes, fertilisers, pesticides, used fuel and water. The final results were referred to the area of cultivation (1 ha). In order to determine the environmental correlations of all the inputs and outputs included in the LCA research and estimate their impact on the environment, the SimaPro application was used, ver. 8.1.0.60. It was, for instance, found that the cultivation of potatoes on smaller plantations affects the natural environment more adversely.
\end{abstract}

\section{Introduction}

Agricultural production severely depletes natural resources; therefore, it places a heavy burden on the environment [13], especially when we consider the use of resources and impact of the production of fertilisers, pesticides and energy on the environment [14]. Furthermore, post-harvest activities, such as transport, storage, processing, packaging and cooling also significantly increase the impact $[6,7]$. The supply chains of food and energy are related to the complex and interconnected environmental and socio-economic impacts [4]. The environmental burden resulting from production processes brings about measurable economic effects which boil down to enormous costs of restoring the balance in the broadly defined natural environment and treatment of people whose diseases are caused by environmental damage. The agricultural sector has been identified as one which adds to the burden on the environment to a great extent, including acidification, eutrophication, toxicity and changes of the climate $[2,3]$. On account of the above correlations between agricultural production and the natural environment, food systems are the main focus of the 2030 Agenda for Sustainable Development, a global obligation to eliminate poverty and hunger, with the simultaneous reduction of environmental and socio-economic effects [17]. The Life Cycle Assessment (LCA) is intended for the analysis and assessment of a potential impact of products on the environment (ISO 14040). In recent years, this method has been

\footnotetext{
* Corresponding author: zbigniew.kowalczyk@urk.edu.pl
} 
more often used for the evaluation of the potential impact of production systems on the environment [16]. It also benefits the agricultural production sector [15]. This approach is a tool for the comprehensive assessment of said environmental impact at all stages of production processes. Its guidelines and rules are contained in ISO standards related to environmental management (ISO 14040), introduced by the International Organisation for Standardisation (ISO) [1]. Many researchers examine broad aspects of the impact of agricultural production on the environment, including [15, 19, 11, 20].

One of the most popular crops in Poland are potatoes; Poland is one of the leaders of potato cultivation in Europe. The potato (Solanum tuberosum L.) is a tuberous crop; it serves an important role in human and animal nutrition and is cultivated under various climatic conditions. It is the fourth most popular crop, after wheat, rice and maize [22]. Potatoes are cultivated the world over within such a wide scope (altitude, latitude and climatic conditions) as no other crop. Furthermore, no other crop can compare to potatoes as regards their nutritional and energy value per unit of area [18].

The issues of the environmental footprint of potato cultivation have been addressed by, for instance, $[12,18]$; however, there is still a deficiency in up-to-date research results within this scope.

\section{Aim, scope, subject and methodology of research}

The purpose of this paper was the comparative analysis of technologies used for potato cultivation on plantations covering areas of various sizes in the context of their impact on the natural environment.

In order to determine the environmental correlations of all the inputs and outputs included in the LCA research and estimate their impact on the environment, the SimaPro application was used, ver. 8.1.0.60. Further, the environmental impact assessment method ReCiPe Endpoint was applied. The Endpoint indicators show the impact on the environment at three aggregation levels, namely: 1) effect on human health, 2) biodiversity, ecosystem and 3) resource scarcity. The environmental impact was calculated in numerical values referred to as eco-indicators $(\mathrm{Pt})$, commonly used in the LCA methodology.

The research was conducted for 10 potato plantations in Proszowice County, Lesser Poland. The region is characterised by especially rich soils of the $1^{\text {st }}$ and $2^{\text {nd }}$ valuation classes.

Table 1 contains general information on the examined plantations. The selection of the plantations was deliberate, in other words five relatively small plantations were picked with the mean areas of 0.63 ha (Group 1) and five larger ones with the mean areas of 2.72 ha (Group 2). The plantations were located relatively close to the farm storage buildings, where potatoes were transported and kept after the harvest (Tab. 1).

Table 1. General information on examined plantations

\begin{tabular}{|c|c|c|c|c|}
\hline Area group & $\begin{array}{c}\text { Surface } \\
\text { Min-max (on } \\
\text { average) } \\
\text { (ha) }\end{array}$ & $\begin{array}{c}\text { Yield } \\
\text { Min-max (on } \\
\text { average) } \\
\text { (t) }\end{array}$ & $\begin{array}{c}\text { Cultivar } \\
\text { (number of plantations) }\end{array}$ & $\begin{array}{c}\text { Distance } \\
\text { Min-max (on } \\
\text { average) } \\
\text { (km) }\end{array}$ \\
\hline 1 & $0,43-0,86(0,63)$ & $19-24(20)$ & $\begin{array}{c}\text { Vineta (2), Denar (1), } \\
\text { Lord (1), Irga (1) }\end{array}$ & $0,4-1,2(0,9)$ \\
\hline 2 & $2,35-3,02(2,72)$ & $23-28(24)$ & $\begin{array}{c}\text { Vineta (2), Tajfun (1), } \\
\text { Denar (1), Irga (1) }\end{array}$ & $0,5-1,9(1,2)$ \\
\hline
\end{tabular}

For the purpose of this work, the "cradle-to-gate" approach was adopted. The system boundaries are shown in Fig. 1. The processes were considered as regards the preparation of soil, organic fertilisation, mineral fertilisation, planting, ridging, chemical protection of plants, harvest and transport to the farm storage buildings. The further processes, involving the storage, preparation for sales, external transport and very sales, were not taken into 
account. The transport of fertilisers, pesticides, seed potatoes and fuel purchased from points of sales to the farm storage buildings was also excluded from the research.

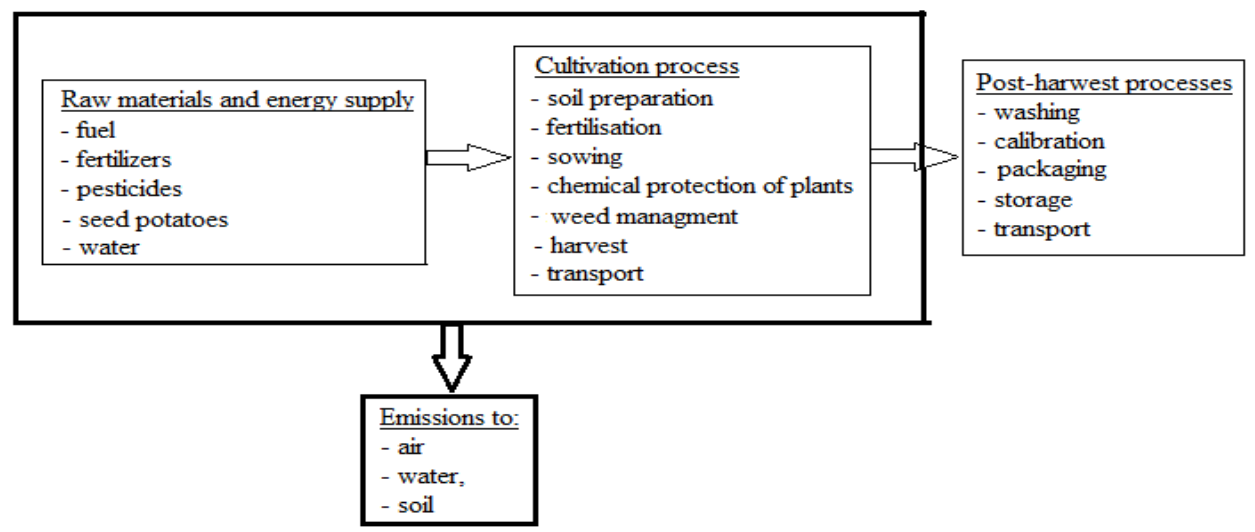

Fig. 1. System boundaries

All the cultivation technologies were fully mechanised; almost no herbicides were used in Group 1 only, whereas weeding was manual. Table 2 lists the means of production used for the cultivation technologies. In general, one may observe the larger unit quantity of means of production in Group 2; the only exception is manure, which the smaller plantations clearly used more often than their larger counterparts. This was mainly attributable to huge costs of manure and difficulties in acquiring large amounts of it, requisite for larger areas of cultivation. Aside from manure, Group 1 used more diesel, which mainly stems from the less effective operation of agricultural machinery on small areas. In addition to the protection of plants with herbicides, each farmer generally used two protective treatments with fungicides and, similarly, two with insecticides. The potato plantations were not artificially irrigated; the consumption of water presented in Table 2 was only related to chemical plant protection.

Table 2. Means of production used for cultivation

\begin{tabular}{|c|c|c|c|}
\hline \multirow[t]{2}{*}{ Description } & \multirow[t]{2}{*}{ Unit } & \multicolumn{2}{|c|}{ Area group } \\
\hline & & 1 & 2 \\
\hline Seed potatoes & $\left(\mathrm{kg} \cdot \mathrm{ha}^{-1}\right)$ & 2490 & 2610 \\
\hline Mineral fertilizers & & & \\
\hline$-\mathrm{N}$ & (kg.ha-1) & 23 & 50 \\
\hline$-\mathrm{P}_{2} \mathrm{O}_{5}$ & (kg.ha-1) & 4 & 12 \\
\hline$-\mathrm{K}_{2} \mathrm{O}$ & (kg.ha-1) & 15 & 54 \\
\hline Manure & (kg-ha-1) & 3400 & 2500 \\
\hline Pesticides & & & \\
\hline - fungicides & (kg-ha-1) & 3,7 & 3,9 \\
\hline - herbicides & (kg-ha-1) & 0,2 & 3,1 \\
\hline - insecticides & (kg.ha-1) & 0,19 & 0,22 \\
\hline Diesel & (1-ha-1) & 177,6 & 145,5 \\
\hline Water & (1-ha-1) & 1680 & 1920 \\
\hline
\end{tabular}

\section{Research results}

By analysing Fig. 2, showing the environmental footprint of potato cultivation in Group 1, one may observe the clear prevalence of planting $(94 \mathrm{Pt})$; this is mostly due to 
the consumption of seed potatoes, whose entire production process imposes a great burden on the environment. Ridging is characterised by the lowest environmental footprint, on the order of 9.6 Pt. The practices which stand out, namely harvest, transport and soil preparation, do not involve the consumption of other materials than diesel, which powers combustion engines of agricultural tractors; however, its consumption still translates into a relatively high level of environmental impact.

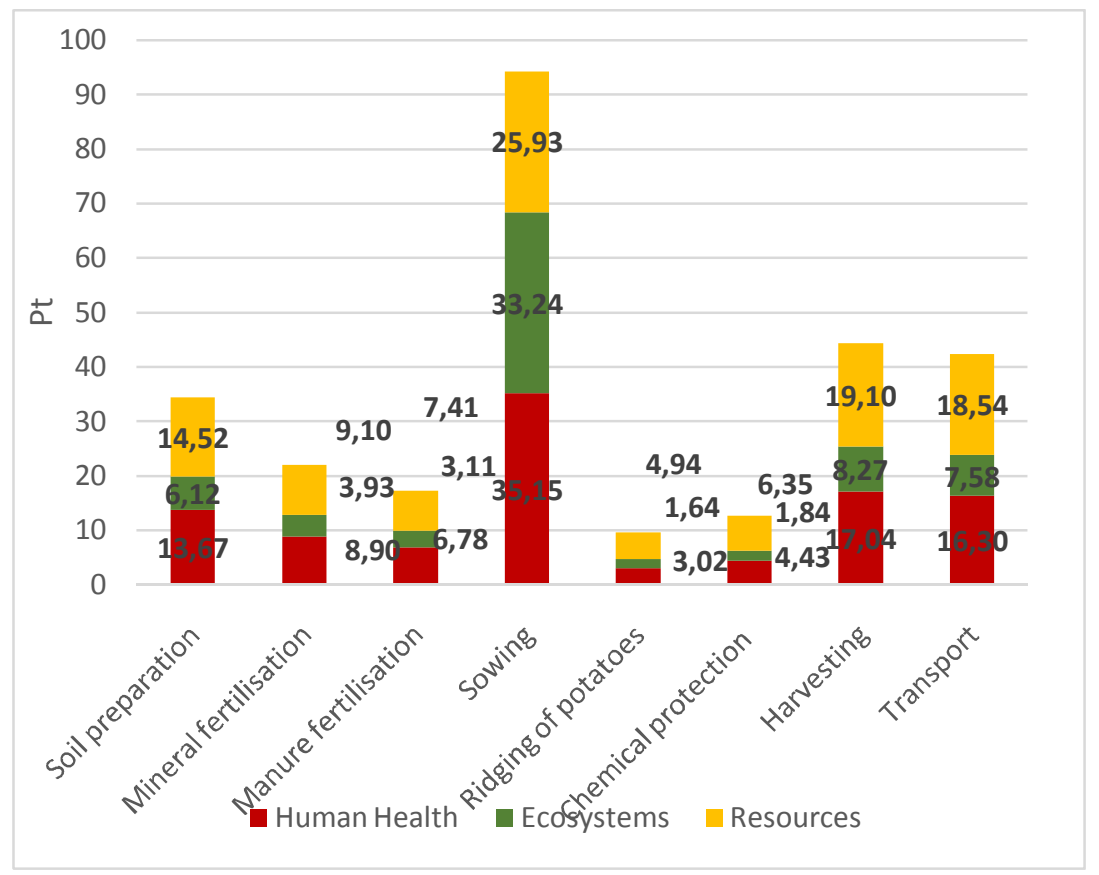

Fig. 2. Environmental impact of technologies in Group 1

Figure 3 presents the environmental footprint of potato cultivation on the plantations of Group 2. Here, in an analogous manner, the greatest impact on the natural environment is exerted by planting the tubers. Methods for the reduction of the number of seed potatoes can be sought in, for instance, their better quality and proper preparation $[8,9]$. One may also notice a smaller (in comparison to Group 1) burden on the environment related to transport $(28.6 \mathrm{Pt})$. This mainly stems from the smaller mass of manure transferred to the farmland (Tab. 2). However, the impact of mineral fertilisation increased, whose greater consumption was to compensate for the smaller amount of manure. 


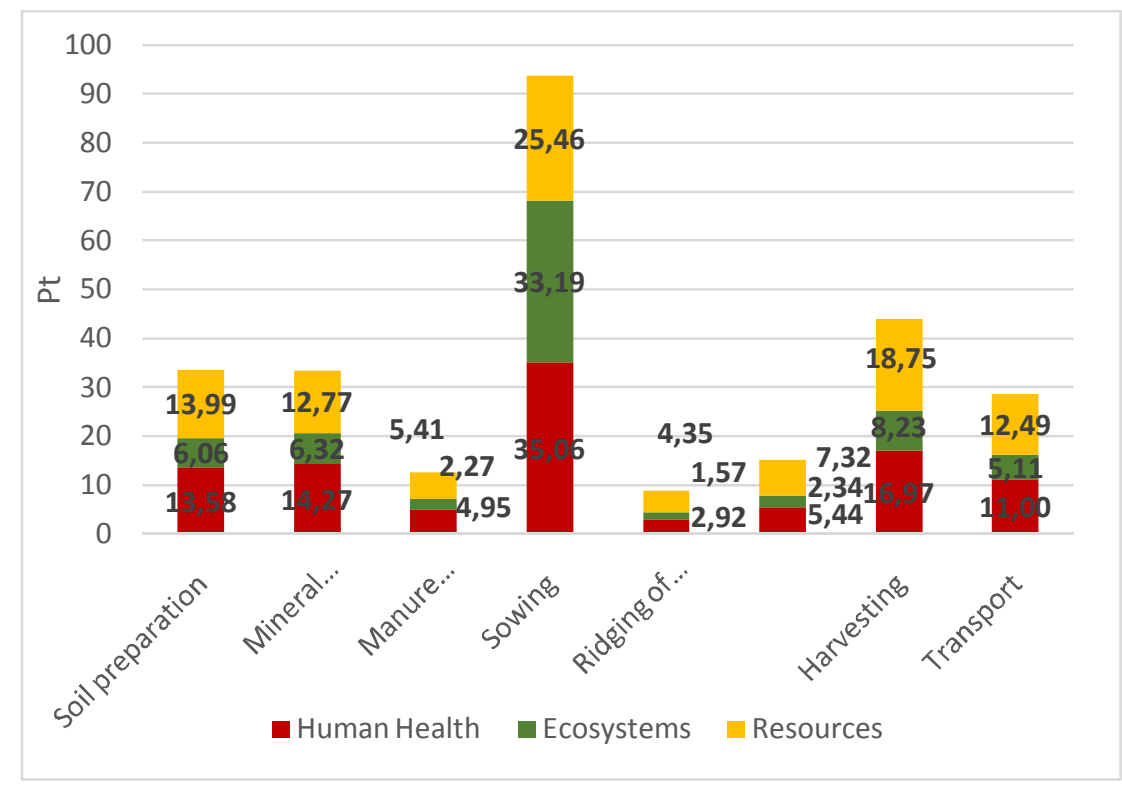

Fig. 3. Environmental impact of technologies in Group 2

The total environmental footprint of the cultivation technologies in both area groups and its structure is shown in Fig. 4. As can be observed, the plantations of Group 1 impose slightly less of a burden on the environment; needless to say, these are the ones covering smaller areas. This, despite the lower consumption of mineral fertilisers and pesticides, is mainly attributable to the greater consumption of diesel (Tab. 2), which in turn is an effect of more time-consuming agricultural practices on the smaller and, frequently, shapeless plantations, as mentioned earlier. Due to the varied calculation methodology and system boundaries adopted for the research, it is difficult to refer the results yielded to the source literature which also contains data on potatoes. In comparison, the environmental footprint of lettuce cultivation according to the same methodology and analogous system boundaries is approx. $200 \mathrm{Pt}[5]$.

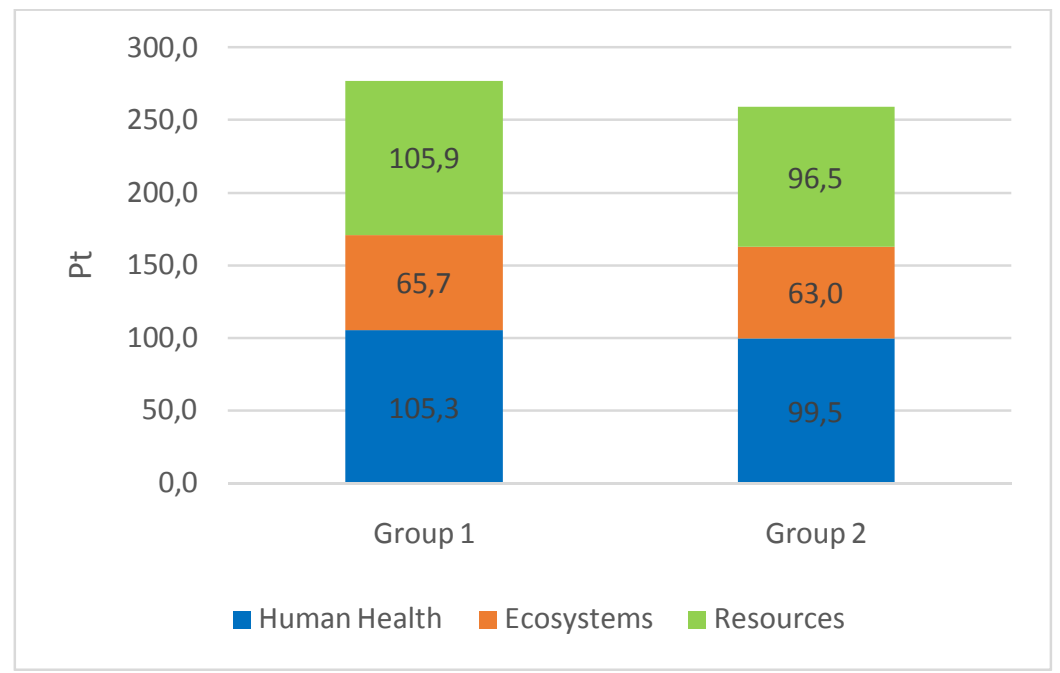

Fig. 4. Total environmental impact structure of potato cultivation technologies in both area groups 


\section{Conclusion}

Based on the analysis of the research results, it has been concluded that:

1. The results presented may serve as basis for making decisions aimed at minimising the negative impact of potato cultivation technologies on the natural environment. It can clearly be seen that the small area of farmland, bound up with land fragmentation, contributes to the environmental burden.

2. Thanks to the identification of the unit processes, as well as all the inputs and outputs, it is also possible to take actions aimed at reducing the consumption of raw materials and energy by the technologies used for potato production which are already highly energyconsuming. The highest environmental footprint of planting, related to the great mass of seed potatoes, should definitely prompt farmers to use their optimal quantities.

3. As regards the total environmental footprint, the dominant position is taken by two items, irrespective of the area of the plantation, namely: Resources $(\mathrm{Pt}=105.9$ and $96.5-$ in Group 1 and 2 respectively), and Human health $(\mathrm{Pt}=105.3$ and 99.5). Potato cultivation affects the Ecosystem to a significantly lower degree; in this case, the eco-indicator Pt in Groups 1 and 2 is 65.7 and 63.0 respectively.

4. The possibility of minimising the hazardous impact of agricultural production on the natural environment should, for instance, be sought in the consolidation and division of arable land, leading to the reduction of land fragmentation and, therefore, the increased area of cultivation.

\section{References}

1. M. Borzecka-Walker, A. Faber, R. Pudelko, J. Kozyra, A. Syp, R. Borek, Journal of Food Agriculture and Environment, 9 (2011).

2. F. Brentrup, J. Küsters, H. Kuhlmann, J. Lammel, Eur. J. Agron. 20, 3 (2004a).

3. F. Brentrup, J. Küsters, H. Kuhlmann, J. Lammel, Eur. J. Agron. 20, 3 (2004b).

4. P.J. Ericksen, Ecol. Soc., 13, 2 (2008).

5. S. Foteinis, E. Chatzisymeon, J. Clean. Prod. 112 (2016).

6. T. Garnett, Food Policy,36 (2011).

7. J. Gustavsson, C. Cederberg, U. Sonesson, R. van Otterdijk, A. Meybeck, Global Food Losses and Food Waste Section 3.2 (Study conducted for the International Congress "Save Food at Interpack 2011, Düsseldorf, Germany) (FAO, Rural Infrastructure and Agro-Industries Division, (2011).

8. T. Jakubowski, Bangladesh Journal of Botany, 45, 5 (2016).

9.T. Jakubowski, Bangladesh Journal of Botany, 47, 3 (2018).

10. A.E. Latawiec, L. Peake, H. Baxter, G. Cornelissen, K. Grotkiewicz, S. Hale, J.B. Krolczyk, M Kubon, A. Lopatka, A. Medynska-Juraszek, B. Reid, G. Siebielec, S.P Sohi, Z Spiak, B.B.N Strassburg, Reconnaissance-scale gis-based multicriteria decision analysis to support sustainable biochar use: Poland as a case study. Journal of Environmental Engineering and Landscape Management, 25, 2 (2017).

11. U. Malaga-Toboła, S. Tabor, S. Kocira, Productivity of resources and investments at selected ecological farms, w: Farm machinery and processes management in sustainable agriculture, 7th International Scientific Symposium / Huyghebaert Bruno, Lorencowicz Edmund, Uziak Jacek (red.), Agriculture and Agricultural Science Procedia, 7 (2015).

12. B. Mattsson, E. Wallén, Acta Horticulturae, 691 (2003). 
13. S. Moll, D. Watson, Environmental pressures from European consumption and production - a study in integrated environmental and economic analysis ETC/SCP Working Paper 1/2009, 24 February 2009. European Topic Centre on Sustainable Consumption and Production, Copenhagen, DK (2009).

14. P. Mouron, T. Nemecek, R.W. Scholz, O. Weber, Ecosystems and Environment, 114 (2006).

15. B. Notarnicola, S. Sala, A. Anton, S.J. McLaren, E. Saouter, U Sonesson, J. Clean. Prod., 140 (2017).

16. P. Roy, D. Nei, T. Orikasa, Q. Xu, , H. Okadome, N. Nakamura, T. Shiina, J. Food Eng., 90, 1 (2009).

17. S. Sala, A. Anton, S. McLaren, B. Notarnicola, E. Saouter, U. Sonesson, J. Clean. Prod., 140, 2 (2017).

18. A. Shahmohammadi, H. Veisi, K. Khoshbakht, Energ. Ecol. Environ., 3, 5 (2018).

19. J. Sikora, M. Niemiec, A. Szelag-Sikora, K. Mudryk, S. Kurpaska, H. Latała, J. Rorat. Evaluation of the properties of waste from African catfish (Clarias Gariepinus B.) farming in the context of using it for agricultural purposes, IOP Conference Series: Earth and Environmental Science, (2019).

20. P. Tylek, M. Pietrzykowski, J. Walczyk, T. Juliszewski, D. Kwaśniewski, Root Croatian Journal of Forest Engineering, 1, 38 (2017).

21. C. Willersinn, S. Möbius, P. Mouron, J. Lansche, G. Mack, .J. Clean. Prod., 140, 2 (2016).

22. M. Zangeneh, M. Omid, A. Akram, A comparative study on energy use and cost analysis of potato production under different farming technologies in Hamadan province of Iran Energy, 35 (2010). 